\title{
Science, Philosophy and the Authority of the Early Franciscan Summa Halensis: Learning from the Past for the Sake of the Future
}

\begin{abstract}
It is generally accepted that the Summa Halensis is an authoritative text insofar as it faithfully reproduces and reflects upon the earliest forms of Franciscan life. But might it not be authoritative in another way too? Contemporary science casts light on many of the systems that shape our sociality and the production of community. Insofar as these scientific understandings converge with the practices and teachings of Franciscan life as detailed in the Summa Halensis, this becomes a text which begins to show an unusual authority. The nature of the transcendentals, the structure of our freedom in ethical decision-making, and natural law, are all areas in which an extensive convergence appears between the Franciscan text and the science of today. This has important implications for our contemporary reception of this text, but it also makes a significant contribution to the on-going dialogue between science and religion.
\end{abstract}

Inevitably the question of authority will be in play in some way when we read a text. What kind of authority is this text claiming; what kind of authority does it have? How should we read it? These are questions that are bound up with issues of authorship and genre in every age, even though they are differently structured in the medieval period than they are today, not least with respect to authorship. The topic at the center of the present study however is whether the early Franciscan Summa Halensis $\mathrm{(SH})$ may have a particular authority in our own contemporary world, which may make it a key text for study today by Franciscan and non-Franciscan alike? We can note that it is a highly innovative text, arguably the first of the medieval Summae introducing an integrated and large-scale 'philosophical theology'. It is a text also which unusually was written by more than one hand (the principal authors were Alexander of Hales and John of La Rochelle). ${ }^{1}$ And it is permeated by the spirit and charismatic life of St Francis of Assisi, whose inheritance flourishes of course down to the present day. The Summa Halensis as a whole can be construed as an attempt to represent in pedagogical form the deeply influential Franciscan charism which extensively shaped the medieval world from the early 13th century.

The new Franciscan movement experienced exceptional levels of growth between 1209 (with 12 friars) and 1260 (with 30,000 friars), and Franciscan friars

1 Lydia Schumacher, Early Franciscan Theology: Between Authority and Innovation (Cambridge: Cambridge University Press, 2019), pp. 4-9. 
had a global reach, extending even to China, by the end of the 13th century. ${ }^{2}$ And it is salutary to recall that in 1992, St Francis was chosen by Time magazine as one of the ten most influential human beings of the last millennium. From the perspective of the afterlife of these texts however, the Summa Halensis appears to lack entirely the kind of authority enjoyed by the widely used Summa Theologiae of St Thomas Aquinas which has repeatedly generated new forms of reception down to the present day. In contrast, this Franciscan text has remained largely in its original Latin and has not been much read outside specialist scholarly circles. The historical profile of the Summa Halensis is considerably less than that of later Franciscan theologians such as Bonaventure and Duns Scotus, who themselves were less central to our medieval inheritance than was the Thomist tradition. The question of a renewed authority for this text today is a bold one, therefore.

But textual authority comes in a variety of shapes and sizes, and today we have at least one source of authority which has only very recently taken shape. We are accustomed to the considerable though also, from a humanistic perspective, piecemeal authority of empirical science, but today an altogether new kind of interdisciplinary science is emerging which is unlocking some of the primary dynamics of human sociality and our power of bonding. This is based in mainstream neuroscience, but extends into evolutionary biology and even into specific areas of physics, where the human is in play. ${ }^{3}$ Of course, the history of the dialogue between science and the humanities has at times been an uneasy one. It may be however that with a new form of scientific interdisciplinarity contributing to our self-understanding as human, we can at last benefit more broadly from the conversation between science and the humanities precisely in those areas of practice - such as our uses of language, our reason and our freedom for instance - which appear to be most fundamental to human life and identity.

A growing priority today is the development of more powerfully critical understandings of human identity as social in order to correct what appears to be a significant imbalance between our technological inheritance on the one hand and our social and environmental values on the other. Arguably we need something akin to a 'second enlightenment', though with its focus now in our social rather than exclusively technological inheritance. With its close proximity to the historical community and values of St Francis and the early Franciscans, the Summa Halensis may be an ideal resource for such a renewed 'enlightenment'. To the extent that the teachings and practices of this text coincide with our interdisciplinary scientific anthropology today, the $S H$ can potentially contribute in important ways to the mediation of that

2 Arnulf Camps and Pat McCloskey, The Friars Minor in China 1294-1955 (St Bonaventure, NY: Franciscan Institute, St Bonaventure University, 1995).

3 Daniel Kahneman's work on judgment and decision-making played an important role here, which began in the 1970s; see especially Daniel Kahneman and Amos Tversky, 'Prospect Theory: An Analysis of Decision Under Risk,’ Econometrica 47:2 (1979), pp. 263-92. In 2002, Kahneman was joint recipient of the Nobel Memorial Prize in Economic Sciences. 
science and to its broader reception. In the context of the need for such a 'second enlightenment', it may be a text which can potentially be shown to have a new kind, and perhaps a new level, of authority.

\title{
Neuroscience and the Self
}

The dramatic rise of neuroscience over the last fifty years or so has, in particular, changed the format of tenacious debates within Western culture around questions of the mind-body relation. The dualist inheritance of Western rationalism in the modern period has become increasingly untenable in the light of new understandings of the human brain as a complex unity of multiple informational systems. These are so closely bound up with how we know and experience the world, that separating mind and body, body and world, becomes impossible. The debates, rather, concern the terms of the interrelation of these elements.

An important voice in the history of this revolution is that of James J. Gibson whose ground-breaking study The Ecological Approach to Visual Perception ${ }^{4}$ set out the principle that human perception occurs within specific environments within which affordances ('opportunities to engage with our environment in ways that reflect our needs and plans') deliver 'a conception of perceiver and environment as co-defined and co-dependent. ${ }^{5}$ In the words of John Teske:

\begin{abstract}
Embodied cognition holds that cognitive processes are deeply and inescapably rooted in our bodily interactions with the world. Our finite, contingent, and mortal embodiment may be not only supportive, but in some cases even constitutive of emotions, thoughts, and experiences. (...) The body plays a central role in shaping the mind even as it requires the latter's control systems to move and act in a real world. 'Thought is action in rehearsal.' Cognition is assembled from neural, bodily and environmental components, including our social relationships. Cognitive dynamics are dominated by interaction. ${ }^{6}$
\end{abstract}

A second milestone was the publication of The Embodied Mind: Cognitive Science and Human Experience by Francesco Varela, Evan Thompson and Eleanor Rosch. ${ }^{7}$ Here there is now the conviction that it is possible to bring together the intricate detail

4 James J. Gibson, The Ecological Approach to Visual Perception (Boston: Houghton Mifflin, 1979). 5 Dave Ward, David Silverman, and Mario Villalobos, 'Introduction: The Varieties of Enactivism,' Topoi 36 (2017), pp. 365-75, on p. 366.

6 John A. Teske, 'Neuroscientific Background to Embodied Cognition,' International Society for Science and Religion (ISSR) website, 'Human Nature and Embodied Cognition: Abstracts from the Conference,' accessed January 13, 2020, https://www.issr.org.uk/projects/human-nature-embodied-cognition/.

7 Francisco Varela, Evan Thompson, and Eleanor Rosch, The Embodied Mind: Cognitive Science and Human Experience (Cambridge, MA: MIT Press, 1991). 
of neuroscience with high level phenomena, and specifically with 'lived human experience'. As the authors put it:

The new sciences of mind need to enlarge their horizon to encompass both lived human experience and the possibilities for transformation inherent in human experience. Ordinary, everyday experience, on the other hand, must enlarge its horizon to benefit from the insights and analyses that are distinctly wrought by the sciences of mind. ${ }^{8}$

We can read this statement as an implicit claim to the possibility of a new kind of relation between science and humanistic disciplines, pointing to the inclusion of 'lived human experience', and so also to the possibilities of 'enlightenment'. There are however two deficits in this project as set out in The Embodied Mind. The first is that they are writing at the earliest stages of the discovery of the pre-thematic (unconscious) 'social cognition system', with its unparalleled speed and interactive density of exchange of social information. It is this which underpins our human powers of face-to-face bonding. Its importance is underlined by later research which shows the fundamentally social character of our embodiment, and the extent to which this is framed in pre-conscious, yet highly evaluative systems. ${ }^{9}$

The second deficit is methodological, and it already points to the very considerable challenges that will inevitably arise in any such 'enlightenment' project. The phrase 'lived human experience' does not give us the content which defines that experience. It is entirely appropriate that The Embodied Mind should define 'experience' here in terms of Buddhist meditative techniques. But why should such practices be detached from their traditional cultural matrix? Religions are long term communities which resist ossification through forms of social transformation that are embedded within the practices and teachings that sustain traditions. Arguably the characteristic feature of religions is not their 'experience' so much as their 'pro-sociality'. ${ }^{10}$ To what extent then can we regard the practice of meditation in Buddhism as formative of tradition? There are long term religious traditions which do not make such meditative practices the focus of their community.

It is the difficulty of giving precise, critical meaning to 'lived human experience' that comes into view here. It may be that we can establish a more constructive point of departure if we allow the resources of interdisciplinary science to come into play.

8 Varela, Thompson and Rosch, The Embodied Mind, p. xv.

9 Chris Frith, 'Social Cognition,' Philosophical Transactions of the Royal Society B: Biological Sciences 363:1499 (2008), pp. 2033-39; Uta Frith and Chris Frith, 'The Social Brain: Allowing Humans to Boldly Go Where No Other Species Has Been,' Philosophical Transactions of the Royal Society B: Biological Sciences 365:1537 (2010), pp. 165-76; Rogier B. Mars et al., 'On the Relationship Between the "Default Mode Network" and the "Social Brain,”, Frontiers in Human Neuroscience 6 (2012), pp. 1-9; Wanqing Li, Xiaoqin Mai, and Chao Liu, 'The Default Mode Network and Social Understanding of Others: What Do Brain Connectivity Studies Tell Us,' Frontiers in Human Neuroscience 8:74 (2014), pp. 1-15. 10 Ara Norenzayan et al., 'The Cultural Evolution of Prosocial Religions,' Behavioral and Brain Sciences 39 (2016), pp. 1-65. 
If neuroscience can offer us a latitudinal perspective of present time and anatomical space, for instance, then this can be complemented with the longitudinal perspective of our past and our becoming which belongs to evolutionary science. Only by working with both equally central scientific perspectives on the human shall we be able to frame a more satisfactory investigation of how 'lived human experience' can be defined. In the following subsection we shall begin to allow these two key disciplines of the human to inform each other.

\section{Enactivism}

Broadly then three streams of neuroscientific thinking have emerged with implications for the nature of the self since the publication of The Embodied Mind, all of which come under the title of 'enactivism'. The first, 'sensorimotor enactivism', focuses on the immediate interactions between the agent and the environment, 'explaining the intentional and phenomenal characteristics of perceptual experience rather than a general account of the mind.'11 Typically this emphasis shuns higher-level, phenomenal or philosophical readings, and centers upon adaptations of living organisms through 'predictive processing' in environmental perception. It is of limited interest for those interested in developing high-level humanistic responses to recent neuroscience.

The second, 'radical enactivism' or 'Radically Enactive Cognition' (REC), marks a point of departure which shares the general concern today to contest the prioritization of a self-sustaining cognitive rationalism, with its suggestions of an untenable dualism. ${ }^{12}$ Indeed, REC seeks to 'cleanse, purify, strengthen and unify a whole set of anti-representational offerings,' where 'representational' implies formally cognitive as distinct from automatic, biological, adaptive responses. REC has an extrinsic rather than intrinsic understanding of representational content (or 'knowledge'), arguing that it is language and the 'scaffolding of our socio-cultural capacities' which explicitly lends representational content to the structures of meaning which are implicit within biological systems. ${ }^{13}$ There is a good case for the view that language plays a key role in establishing representational content in modern human beings. But here we encounter a difficulty. The linguistic sign consists both of the materiality of words which are spoken as sound or written as shape, and the concepts which are embedded in or through words. The radical hiatus between biology and representation in REC raises the question as to whether due account has been given to the material nature of the linguistic sign itself, and specifically to the embeddedness of advanced language, as material form, in the human brain.

11 Ward, Silverman, and Villalobos, 'Varieties of Enactivism,' p. 370.

12 Daniel D. Hutto and Erik Myin, Evolving Enactivism: Basic Minds meet Content (Cambridge, MA: MIT Press, 2017).

13 Ward, Silverman, and Villalobos, 'Varieties of Enactivism,' pp. 370-73. 
From the perspective of a humanistic ambition to integrate the interdisciplinary science of the human and 'lived human experience', in the interests of an 'enlightenment', it is the third, 'enactivist' school which shows most promise. 'Autopoietic enactivism' seeks to 'ground cognition in the biodynamics of living systems.' An example here might be the way in which an organism such as a bacterium feeds upon the sucrose in its environment:

That sucrose is a nutrient is not intrinsic to the status of the sucrose molecule; it is, rather $a$ relational feature, linked to the bacterium's metabolism. Sucrose has significance or value as food, but only in the milieu that the organism itself brings into existence. ${ }^{14}$

This perspective involves commitments to 'the strong continuity of life and mind the view that the organizational structures and principles distinctive of mind are simply enriched versions of the structures and principles grounding life itself. ${ }^{15}$ This third form of 'enactivism' is also that which is specifically associated with the human social cognition system. This system has played a central role in developing understandings of the human not only as relational and social, but also as linguistic.

\section{Enactivism and the Social Cognition System}

We can define the social cognition system in terms of the 'study of information processing in a social setting. ${ }^{, 16}$ In the words of Ivana Konvalinka:

When we interact with another person, our brains and bodies are no longer isolated, but immersed in an environment with the other person, in which we become a coupled unit through a continuous moment-to-moment mutual adaptation of our own actions and the actions of the other. ${ }^{17}$

These multiple reflex interactions occur at speeds well below the threshold of conscious perception, but they nevertheless communicate to consciousness a sense of 'rapport'. ${ }^{18}$ As 'complex, multi-layered, self-organizing,' they sit within the early

14 Ward, Silverman, and Villalobos, 'Varieties of Enactivism,' p. 369.

15 Ward, Silverman, and Villalobos, 'Varieties of Enactivism,' p. 370. Here 'autopoietic enactivism' shows a considerable debt to the sophisticated philosophy of Hans Jonas, who develops the principle 'life can only be known by life,' thus assimilating 'life' and 'mind'. See Hans Jonas, The Phenomenon of Life: Towards a Philosophical Biology, trans. L. Vogel (Evanston, IL: Northwestern University Press, 2001).

16 Frith, 'Social Cognition,' p. 2033.

17 I. Konvalinka and A. Roepstorff, 'The Two-Brain Approach: How Can Mutually Interacting Brains Teach Us Something About Social Interaction?' Frontiers in Human Neuroscience 6, no. 215 (2012), pp. $1-10$, on p. 2.

18 Linda Tickle-Degnen and Robert Rosenthal, 'The Nature of Rapport and its Nonverbal Correlates,' Psychological Inquiry 1:4 (1990), pp. 285-93. 
motor system, involving sets of mutual responses ranging from eye movement, facial expression, posture and gesture to the synchrony of brain waves, breathing and pulse: a subtle and pervasive 'alignment of behaviour' which includes 'synergies, co-ordination and phase attraction. ${ }^{19}$ Empathy, affectivity, and evaluation all combine with high levels of pre-thematic reflexivity, involving self-monitoring and monitoring of the other, as well as any third party observers who may be present, during this process of many and diverse forms of 'internal information processing. ${ }^{20}$ Here too evaluative processes integrate first-hand knowledge of the other gained in the moment and a second-hand, associative knowledge acquired from other sources. ${ }^{21}$

Within the 'social cognition system' then, the evaluative protocols of one person are densely exposed to the evaluative protocols of another. Such a system has to be understood as a form of pre-thematic reflexivity which is extensively conditioned by an environment of interactive, physical-social complexity. Moreover, this is an environment in which pre-thematic and thematic activity combine in the sense that those brain areas which are associated with advanced social reasoning are also extensively integrated within pre-thematic, reflex-centered social networks. From an 'enactivist' perspective, Di Paulo and De Jaegher refer to social cognition not only as 'self-organizing' but also as our 'participatory sense-making' of the human other. ${ }^{22}$ These two terms capture the binaries of objectivity and subjectivity, self and other, self and world.

The enactive phrase 'participatory sense-making' neatly straddles the pre-thematic on the one hand, and close conversation between self-aware, linguistic subjects on the other. ${ }^{23}$ These are continuous systems, therefore, but they are distinct in the extent to which our recently evolved advanced linguistic consciousness allows us freely to choose whether or not we shall engage with the other person and for how long. ${ }^{24}$ We should think of our advanced linguistic consciousness then as evolving out of the pre-thematic, interactive, informational exchanges of our social cognition, bringing a wholly new power of conscious decision-making. But our advanced language does not remove us from materiality. Rather, it constitutes a domain of freedom which is operative precisely within the material world order. From the perspective of classical rationalism, the challenge has been how to explain the relation between body and mind (between efficient causation and consciousness), which David Chalmers has called 'the hard

19 E. Di Paolo and H. De Jaegher, 'The Interactive Brain Hypothesis,' Frontiers in Human Neuroscience 6:163 (2012), pp. 1-16, on p. 1.

20 L. Schilbach et al., 'Toward a Second-Person Neuroscience,' Behavioral and Brain Sciences 36:4 (2013), pp. 393-414.

21 R.J. Seitz, M. Franz, and N.P. Azari, 'Value Judgments and Self-Control of Action: The Role of the Medial Frontal Cortex,' Brain Research Reviews 60:2 (2009), pp. 368-78; B. Kuzmanovich et al., 'A Matter of Words: Impact of Verbal and Non-Verbal Information on Impression Formation in High Functioning Autism,' Research in Autism Spectrum Disorders 5 (2011), pp. 604-13.

22 Di Paulo and De Jaegher, 'The Interactive Brain Hypothesis,' pp. 1, 2-4.

23 Ezequiel Di Paolo, Elena Clare Cuffari, and Hanne De Jaegher, Linguistic Bodies: The Continuity Between Life and Language (Cambridge, MA: MIT Press, 2018).

24 Nicholas Shea, 'Concept-Metacognition,' Mind \& Language (2019), pp. 1-18. 
question'. ${ }^{25}$ From an autopoietic enactivist perspective however, the question is rather different: 'how do mind and matter work together?' This sits well with the question of our freedom, since it is difficult to ask what freedom is. It is wiser to phrase the question in terms of 'what makes us free?' What is at work in us when we feel, act and think in ways which we experience as free?

\section{Advanced Modern Language}

It was the linguist Ferdinand de Saussure who first argued that when we speak or write, we necessarily choose our spoken or written words (paroles) from within the system of language (langue) itself. ${ }^{26}$ Those with whom we speak will hold us responsible for what we say, just as we will hold others responsible for what they say. Allowing ourselves to become fully present in our words when we speak with others is fundamental to communication, negotiation and trust, and so also to human flourishing. Here de Saussure is pointing to the fact that it is this power to choose our words which sets us free. How then do words give us that freedom?

Our question concerns the origins of advanced modern language which gives us the advanced linguistic consciousness of anatomically and behaviorally modern human beings. Talon sticks appear in the archaeological record from around 20,000 years ago which point to emergent skills of mathematics. ${ }^{27}$ We see evidence for the presence of complex and coordinated social spaces, complex burials, and, arguably for the first time, full reproductions of the human face from around 10,000 years ago. ${ }^{28}$ It was in this period of the Neolithic that a relatively sudden growth in population size occurred, reflecting the change from a nomadic to an agrarian economy. The need for new forms of cohesion, in larger groups, may also underlie the presence of ritual. ${ }^{29}$ Vittorio Gallese has argued that the occurrence of forms of systematic or pre-planned violence from around 10,000 years ago also points to

25 David J. Chalmers, 'Facing Up to the Problem of Consciousness,' Journal of Consciousness Studies 2:3 (1995), pp. 200-19.

26 F. de Saussure, Course in General Linguistics, trans. R. Harris, 3rd ed. (Chicago: Open Court, 1986), pp. $9-10,15$.

27 J. de Heinzelin, 'Ishango,' Scientific American 206 (1962), pp. 105-16.

28 Ian Kuijt, 'The Regeneration of Life,' Current Anthropology 49:2 (2008), pp. 171-97. Arguably the reproduction of the face of another is bound up with the fifth of Robin Dunbar's five forms of intentionality; see Robin Dunbar, The Human Story (London: Faber and Faber, 2004), pp. 41-76.

29 Robert N. Bellah, Religion in Human Evolution: From the Paleolithic to the Axial Age (Cambridge, MA; London: Harvard University Press, 2011), pp. 1-43; C.S. Alcorta and R. Sosis, 'Ritual, Emotion and Sacred Symbols,' Human Nature 16 (2005), pp. 323-59; Robin Dunbar, 'The Origin of Religion as a Small-Scale Phenomenon,' in Religion, Intolerance, and Conflict, ed. Steve Clarke et al. (Oxford: Oxford University Press, 2013), pp. 1-21. 
the presence of advanced language since a generation needs to be raised who can name another group as 'non-human'.30

Of course, the relatively recent appearance of advanced linguistic consciousness needs to be placed against the background of more basic processes which come into view much earlier in our evolutionary history. For instance, the first evidence for the working of stone tools dates from 3.3 million years ago, near Lake Turkana in Kenya. ${ }^{31}$ These techniques involved the capacity to 'see' a tool, or a better tool, hidden in the stone. Tool making and tool use already show a certain structure involving the internalization within the brain of an external object (here the external stone becoming a tool in the hand) from one perspective, and the penetration of the mind into the environment through applying the tool, from another, potentially doing so in imaginative ways which reshape our environment. Only a creature with imagination can internalize the world, and yet also enter into our environment, shaping it from within. We can link this structure with the fundamental principle of inhalation-exhalation' as found in biology, with the original emergence of multicellular eukaryotes as a prelude to life, or indeed with the consumption of sucrose by the microbe quoted in the section on autopoietic enactivism above. In contemporary evolutionary thinking ('the extended evolutionary synthesis'), this structure is represented by the powerful concept of 'niche-construction' as a property of all life. ${ }^{32}$ Living creatures move and so interact with the environment, undergoing change.

It is difficult for us to understand today, however, just how extensive tool making and tool use must have been in the hunter gatherer communities of our evolutionary past. The 'lithic landscapes' discovered by archaeologists suggest widespread processes of apprenticeship, learning and teamwork, involving carrying, storing and preparing stones, at all levels of society. ${ }^{33}$ With its complex sequences of percussive

30 V. Gallese, New Scientist 221:2952 (2014), p. 1.

31 Agustin Fuentes, The Creative Spark: How Imagination Made Humans Exceptional (New York: Penguin Random House, 2017), p. 31.

32 The ground-breaking work in this respect is F.J. Odling-Smee, K.N. Laland, and M.W. Feldman, Niche Construction: The Neglected Process in Evolution (Princeton, NJ; Oxford: Princeton University Press, 2003). Our human niche-construction is distinctive in what has been called a 'ratcheting effect', in which our sociality and our technology alternate and combine as drivers of brain development; see C. Tennie et al., 'Ratcheting up the Ratchet: On the Evolution of Cumulative Culture,' Philosophical Transactions of the Royal Society of London B: Biological Sciences 364:1528 (2009), pp. 2405-15.

33 D. Stout and T. Chaminade, 'Stone Tools, Language and the Brain in Human Evolution,' Philosophical Transactions of the Royal Society of London B: Biological Sciences 367:1585 (2012), pp. 75-87; E.A. Cartmill et al., 'A Word in the Hand: Action, Gesture and Mental Representation in Humans and Non-Human Primates,' Philosophical Transactions of the Royal Society of London B: Biological Sciences 367:1585 (2012), pp. 129-43; Peter Hiscock, 'Learning in Lithic Landscapes: A Reconsideration of the Hominid “Toolmaking” Niche,' Biological Theory 9:1 (2014), pp. 27-41. It is estimated that it would take 'ten to twenty five pounds of stone and about 50 to a 100 flake tools' to strip the meat from a small wildebeest, which committed these small communities to very high levels of cooperation (Fuentes, The Creative Spark, p. 62). 
'strikes', its repetition and imitation, tool making and use also points forward to the large-scale learning of 'words' (as sounds and later as the shapes of writing) and the sequencing of syntax. ${ }^{34}$

The extent of the leap to advanced modern language can be judged by the fact that one of its primary characteristics is the 'arbitrary' nature of the link between words and their meanings. With some few exceptions, our advanced language shows no 'natural' association between words and what they mean (as occurs in 'biological' language for instance). The neurologist and philosopher Andy Clark observes that these internalized words and phrases of advanced modern language are in effect so many 'material objects' that 'press minds like ours from the biological flux.' ${ }^{35}$ In their tool-like nature, they are 'potent real-world structures' (of sound or shape) which ground the 'neural wet-ware' of consciousness, helping us to consolidate and objectify through material form what it is that we think. ${ }^{36}$ The material properties of words are internalized in the so-called 'semantic system' in the cortex, where they are also networked with their respective concepts. ${ }^{37}$ Even the most intuitive and advanced mathematical computations have been found to show a material base in language. ${ }^{38}$ It seems then that the sense we have of being free in what we choose to believe or do, cannot take place in some 'detached' or 'abstract' space but must in fact always take place immersively, within the material contexts of language, embodiment and world.

\section{Freedom and the Material Sign}

As human beings, we appear to have a capacity to enter ever more deeply into our environment, through this ability to 'see' in the world around us what is not there but which could be there. And we have a parallel capacity to internalize what is outside or beyond us, both in tool making and use, and in language learning and use. Tool use and language use represent two sequential levels of 'niche-construction' then in our evolutionary history. ${ }^{39}$ But here we are confronted with a different kind

34 D. Lombao, M. Guardiola, and M. Mosquera, 'Teaching to Make Stone Tools: New Experimental Evidence Supporting a Technological Hypothesis for the Origins of Language,' Nature: Scientific Reports 7:11 (2017). Published online 31 October 2017. DOI: 10.1038/s41598-017-14322-y.

35 A. Clark, Supersizing the Mind: Embodiment, Action and Cognitive Extension (Oxford/New York: Oxford University Press, 2011), pp. 44-60.

36 Clark, Supersizing the Mind, p. 56.

37 A.G. Huth et al., 'Natural Speech Reveals the Semantic Maps that Tile Human Cerebral Cortex,' Nature 532 (2016), pp. 453-58. Published online 27 April 2016. DOI: 10.1038/nature17637.

38 A. Clark, 'Language, Embodiment and the Cognitive Niche,' Trends in Cognitive Sciences 10:8 (2006), pp. 370-74; S. Dehaene et al., 'Sources of Mathematical Thinking: Behavioral and BrainImaging Evidence,' Science 284:5416 (1999), pp. 970 -74.

39 Christ Sinha, 'Niche Construction, Too, Unifies Praxis and Symbolization,' Language and Cognition 5:2 (2013), pp. 261-71. 
of question: if niche-construction is about 'being at home' in our environment, how then can we be at home in the linguistic consciousness which now defines us? We can frame this question differently. If advanced language sets us free, how then can we be at home in this universe when on all sides we appear to encounter material limit, whether as weak or ill, as confined or excluded, as tired or hemmed in, as vulnerable or mortal? And we also appear to be surrounded by the unending complexity of the world which disrupts our power to make clear decisions.

But interdisciplinary science may have something to contribute here. Today we know that there is indeed a point of unity between mind and body, mind and world, and it is precisely this internalized system of signs which constitutes language within us. These signs are both physical, located at precise points in the brain, and also constitute the self-possessing, free consciousness that we are. What practices might there be then arising from this structure which allow us to experience this unity, and 'at homeness', even if we cannot understand it?

We are at home where we practice the unity of body and mind. And we practice this unity where we consciously or freely celebrate the materiality of signs as these exist within us. Through ritual or ritualistic practices, in which we speak, sing, chant or write (calligraphy) with others, we are tacitly agreeing with others to highlight, even to celebrate, the materiality of the sign. ${ }^{40}$ This may enhance the meanings of the words used or, alternatively, it may serve to reduce their semantic importance, even to the extent of excluding their conceptual meanings. But in their use of repetition, rhymes, rhythms, harmonies, synchronies, music and dance, we can say that ritualistic practices foreground the material rather than the semantic properties of language as signs.

This certainly sets ritual apart from conventional discourse. In effect, ritual emphasizes the non-controlling, openly social, dimensions of language and so allows our advanced language - which in its relation to tools is itself a primary system of control - to become saturated with the deep, fast, interactive harmonies and synchronies of the human social cognition system. In ritual practices the 'local' face to face harmonies of our biological relating are enhanced and extended within an expanded environment, setting up a repeated harmonic resonance which can shape even larger scale societies. ${ }^{41}$ And of course we also find such repetition in

40 The philosopher Wilfred Sellars argued that we are inextricably caught between 'the manifest image of the "man in the world," which is our personal experience, and the "scientific image' which derives from rigorous experimental resources; see Wilfred Sellars, 'Philosophy and the Scientific Image of Man,' Frontiers of Science and Philosophy, ed. Robert Colodny (Pittsburgh, PA: University of Pittsburgh Press, 1962), pp. 35-78. A modern scientific understanding of the linguistic sign as that which can become the object of our intentional celebration, potentially offers a practice-centered account of the overlap between these two images.

41 Gary Bente and Eric Novotny, 'Bodies and Minds in Sync: Forms and Functions of Interpersonal Synchrony in Human Interactions,' in Handbook of Communication Science and Biology, eds. Kory Floyd and René Weber (Routledge: Taylor \& Francis, 2020). 
the arts (with rhyme, for instance) or in dance with rhythm. Such communal emphasis upon the material medium of communication, which all human beings profoundly share, marks out the spaces in which we can experience an 'at homeness' in the world as advanced linguistic consciousness. If tool use marks the first occurrence of our evolutionary 'internalization-externalization' dynamic, and advanced language is the second occurrence of this dynamic, then arguably its third occurrence takes place when linguistic consciousness freely practices and displays its unity with material embodiment by celebrating the materiality of the sign. Here freedom affirms its source as freedom, thus - in practice - embracing the unity of free self and material world, in a way that points forward to a cosmic understanding of the self.

\section{Freedom and Reason}

But ritualistic practices in themselves cannot complete the sense we have of belonging in the world. For such a completion we have to consider the processes of reasoning which are at the center of our linguistic consciousness. We are defined in our humanity by the power of discernment, judgment and decision. We can argue then that it is at the point of judgment and resolution that we most truly become ourselves, as self-possessing, intelligent consciousness in a complex world. But as embodied consciousness, we are also contextual creatures. How we reason is also influenced by the contexts in which we reason.

It is the work of mind to reason towards decision and judgment. But in fact there are three distinct ways in which we commonly do this. In each of these three moments, mind resolves itself in the context of judgment, and we realize ourselves as free. The first of these occurs where we adopt the posture of an observer, as we do in scientific judgments for instance. To be an observer is to impose a certain distance between ourselves and the world (epitomized in the act of measurement). Here we can tolerate minimal complexity since what counts is that we have a reliable answer. We may have to prioritize reducing the complexity by refining the question, and we may need to extend the deadlines. As far as possible, the outcomes of 'theoretical reasoning' need to be irrefutable. Here the process of arriving at valid judgment manifests a certain kind of freedom and so also 'at homeness' in the world, but it is one which is conditional. It depends upon the narrowing down of the question and so also the relative controlled exclusion of the world, in order to strip out and to manage the complexity which would otherwise disrupt this kind of reasoning. The freedom which is characteristic of theoretical reasoning is a freedom from.

The second way in which we make ourselves at home in the world through reasoning, resolution and coming to judgment is when we act as agent. But again, this is only a conditional 'at homeness'. In this case, we are concerned with doing and so also with 'practical' reasoning: how can I reasonably get what I want or need in 
this situation? How can I meet my body's needs ${ }^{42}$ Once again the sheer complexity of reality will threaten to undermine our capacity to reason in ways that allow us to be fully at home in the world. In this case we reduce situational complexity by filtering it through the lens of my own needs and wants. I do not have to engage with the world's complexity except in so far as it is the context in which I pursue my specific needs. In fact, when I reason concerning how to act in dynamic, social situations, in pursuance of my goals, my practical reason can never deliver the secure knowledge which is retrievable through my theoretical reasoning in questions of science for instance. For the agent, in the flow of life, there can only be the balance of probabilities. Here there is no irrefutability, since the world's complexity cannot be wholly excluded. But there is the irreversibility of what I may finally choose to do. We make ourselves at home in the world then through practical reason, but once again we do so only conditionally. This 'at homeness' now manifests not as a freedom from but rather as a freedom to.

Our third kind of reasoning then, which we can call 'community reasoning', is altogether of a different kind. Here it is presupposed that I am reasoning in the presence of another human being. Since I am seeking to come to a decision inclusively, with them, rather than exclusively about them, I can no longer 'reduce' the complexity of the other person by either turning them into a statistic or by instrumentalizing him or her, in the light of my own needs and desires. Rather, in my 'community reasoning', I shall need to recognize the equality of the other unconditionally, which means to say with the openness we associate with the bonding of friendship.

The difference between the openness of 'community reasoning', with its freedom in, and the conditional openness of our freedom from and freedom to, is that it locates us as self-aware, self-possessing consciousness precisely within the activated social cognition system, with the unparalleled densities of its information exchange. ${ }^{43}$ The processes of evaluation in our social cognition are unconditionally open-ended forms of openness as mutual 'participative sense-making'. Moreover, the foundations of our social cognition are centrally self-organizing, so that our freedom in the body is simultaneously our freedom in the world. Our freedom in relationship, through renunciation of control, opens into the freedom of our deep belonging in the world and at homeness in this world. Given the nature of the self-organizing harmonics of the social cognition system, perhaps we can even say that in this openness of belonging, with its mutual recognition of equality, the world itself, with its deep-set and originary harmonies, is effectively receiving us.

42 On 'practical' or 'motive reasoning', see Paul D. Janz, The Command of Grace: A New Theological Apologetics (London; New York: T\&T Clark, 2009), pp. 79-95. Janz discusses what he terms 'finality of non-resolution' as a committed remaining with the impossibility of conclusive rationalization, as in the case of tragedy for instance, in Paul D. Janz, God the Mind's Desire: Reference, Reason and Christian Thinking (Cambridge: Cambridge University Press, 2004), pp. 19-23.

43 Schilbach et al., 'Toward a Second-Person Neuroscience.' 


\section{The Physics of Symmetry}

This brings us to the science of physics, and the theme of 'symmetry'. Symmetry denotes repeating patterns in which the same figures and proportions occur (such as the wings of a butterfly, or the two, almost identical halves of a human face). Physicists distinguish between 'translational symmetry' (the laws of physics are the same everywhere, and do not change with time), for instance, and 'rotational symmetry' (the kettle does not cease to be a kettle, when it is turned around). The strangest and most direct kind of 'translational symmetry' is found in the speed of light, which is a constant. It remains the same for us regardless of the speed at which we may ourselves be travelling when we measure it. This insight is a key element in Albert Einstein's 1905 paper on 'special relativity'. We can see the effects of this 'translational symmetry', or 'translational invariance' as it also called, in the case of a car engine, following Andrew Steane, who states: 'The workings of the engine do not change - they are invariant - when the location of the car is changed or "translated" from one place to another."44

The image of a car engine working in more than one place may seem entirely normal to us. Of course, the engine will not work when the ambient temperature drops below a certain degree or above another. But within these limits, the car does work and so we can say that its status as a harmonious system, which accords with the laws of physics, is preserved. The same kind of system, with its supporting mathematical equations, can be reproduced many times, as happens on the car engine production line. Individual car engines are harmonic systems which accord with physical laws and their mathematical expressions, and for as long as this system can be preserved, they will work. But as Steane stresses, such a system can only be produced since we live in a universe which allows such systems to occur.

It is often said that cause and effect, or efficient causation, is the dominant logic of the universe: how one thing affects another. But in reality, there are two systems at work. In addition to efficient causation, we need also to take account of the second, which is symmetry:

The symmetry principle already makes its contribution before we ever write or discover the formulas and equations, because it places conditions on what sorts of equations could make sense. And science is all about making sense, or finding the sense that can be made. Symmetry principles in fact play an important role, because they amount to meta-laws which express higherlevel principles that basic laws of motion must respect if they are to make certain types of sense. ${ }^{45}$

44 Andrew Steane, Science and Humanity (Oxford: Oxford University Press, 2017), p. 24.

45 Steane, Science and Humanity, p. 25. 
There are two dimensions in play here then. The first is the individual parts of the car engine, each of which needs to work in an appropriate way. But secondly there is the whole: all the parts together:

The truth of the whole in this example is the simple but important observation that the functioning of a car engine does not depend on the location of the car. The truth of the parts is the behaviour of the pistons and fuel and the equations that describe them. The physics and chemistry of those motions have translational invariance [my italics], and this is an important, insightful, and simplifying observation that gets to grips with the big picture without needing to trouble about the details. This truth about the whole is not negated by the truths about the parts. ${ }^{46}$

\section{Were symmetry not present,}

then the engine would depend on the location of other things after all, and therefore could not be described only in terms of itself and its immediate environment. So the claim that the symmetry 'just happens' to emerge from the equations of motion of the car engine is wrong. As soon as you even suppose that there is an equation for the car engine, it must have this symmetry. ${ }^{47}$

Steane states further regarding the history of physics during the modern period:

Much of the progress in fundamental physics in the twentieth century can be seen as a sequence of triumphs of reasoning from symmetry. Furthermore, these insights survived the huge transition from classical to quantum physics that took place in the twentieth century. That is a very striking fact. It illustrates that the symmetry principles have a validity in their own right, independent of the underlying language (that is, classical properties or quantum operators) in which they are expressed. As Philip Anderson (Nobel Prize for Physics, 1977) put it in a famous paper: 'it is only slightly overstating the case to say that physics is the study of symmetry. ${ }^{.48}$

He also emphasizes for us here that:

The symmetry principle is first a guide, and then, in a certain hard-to-express but beautiful sense, it 'inhabits' the equations of physics. The concrete phenomena that are in the world are a sort of physical embodiment of the symmetry principles. By moulding our mathematical notation, such insights shape the very way we 'see' the world. ${ }^{49}$

In conclusion then, there are two kinds of causation: efficient causation which builds from below and symmetry which seemingly descends 'from above', enabling the possibility of 'translational invariance' and, with that, the emergence of discrete 'things' (composed of parts). If we are to be part of a 'world', then things need to remain in existence long enough for us to identify them. But things must not last forever. Between the two there is a habitable world.

46 Steane, Science and Humanity, p. 25.

47 Steane, Science and Humanity, p. 25.

48 Steane, Science and Humanity, p. 28.

49 Steane, Science and Humanity, p. 28. 
In sum, the term 'symmetry' refers to the principle of connectedness, which allows 'translational invariance' to occur, lending our world stability, or existence. That this is a basic principle of existence is borne out by the fact that light itself displays an absolute degree of 'translational invariance'. The speed of light (around 300,000 kilometers per second) is invariable everywhere in the universe and, as stated, this is unaffected by our own speed at the point of its measurement. It follows then that 'symmetry' is not a mere construct or 'way of seeing things.' It is rather a fundamental law of the universe: the primary law even which conditions all else, making 'world' itself possible, and all the things that are within it. And we see that symmetry as simplicity and beauty.

\section{Human Identity and 'Translational Invariance'}

Since we are embodied forms in a material universe, the rules of 'translational invariance' will apply to us too, though now in 'human' ways. We can cite the fact that the millions of cells which constitute the body are constantly being renewed while my body remains my own. I essentially remain the same person I was when I was growing up far away from where I am now, all those years ago. My continuing identity over space and time then shows that I am by nature 'translationally invariant'. But within this continuation, something else lurks which is the extent to which I grow as a person, undergoing or meeting change and yet still remaining the person I am; or indeed becoming the person I can potentially be. Life constantly challenges us, and we find we have to make important social decisions about the values we hold and how we shall act. Our ability to act with integrity, points to our constancy within change. We are different then from engineers who build car engines in that human 'translational invariance', beyond its natural occurrence, is something we have to 'create' ourselves. And we do that through processes of decision-making which determine the kind of person we are and the kind of person we can be. Here constancy and responsibility are in play as vitally important social factors.

Furthermore, the neuroscience of free will and decision-making suggests that harmony (which presupposes symmetry) is in fact also a key factor in the ways in which we change, grow or 'become'. Robert Kane, a leading scholar in this field, describes the 'hot' conditions of conflicting possibilities of identity which exist when we are confronted with a significant ethical challenge. These represent 'movement away from thermal equilibrium - in short a kind of stirring up of chaos in the brain that makes it sensitive to micro-indeterminacies at the neuronal level. ${ }^{50}$ The human brain is 'a parallel processor (...) which can simultaneously process different kinds of information relevant to tasks such as perception or recognition through dif-

50 Robert Kane, 'Rethinking Free Will: New Perspectives on an Ancient Problem,' in The Oxford Handbook of Free Will, ed. Robert Kane, 2nd ed. (Oxford: Oxford University Press, 2011), p. 387. 
ferent neural pathways.' This processing capacity is 'essential to the exercise of free will.'51

There are two complementary systems in play here. The first is 'bottom-up' and conflicted, with competing possibilities of action and therefore identity, while the second is 'top-down', leading to harmonization, integration and the global unity of the self..$^{52}$ We make such ethical decisions by inhabiting the different competing images of the self as these combine and re-combine in the brain. These inform our ethical decision-making as inherent possibilities which can subtly be explored. ${ }^{53}$ The key to difficult ethical decision-making, in which none of the initial possibilities appear to allow resolution, is time, effort and finally the formation of new neural pathways in the brain through the top-down effect. These create the possibility of a new future and identity, and they constitute 'growth'.

To be human therefore is to be repeatedly challenged by the need to change in the face of a changing world, but in ways which show that what deeply identifies 'me' for others (and for myself), remains a constant. Here 'translational invariance' is in play in the human person: indeed, it is at the core of who we are and our sense of being at home in the world. In such key moments of decision-making, most of us will seek the advice of those who know us well. This deeply rooted pursuit of the 'right thing to do' marks us out as creatures who are capable of attaining high levels of harmonization in the brain. Such processes of harmonization which straddle the subjective-objective divide allow us an enhanced sense of belonging in the world, and, with that, a more secure and potentially productive openness to the future.

\section{Contemporary Science and the Summa Halensis}

What kind of echo, if any, do we find of this contemporary scientific account of our human sociality in the strongly social early Franciscan text we know as the Summa Halensis? Firstly, we need to recognize that it does indeed have unusual contexts. The philosophies and religious imagination of the $\mathrm{SH}$ were constructed in direct dialogue with the charismatic life of St Francis of Assisi. The early growth and long-term flourishing of the Franciscan Order suggests that the early teachings and practices of the Order must have extensively harnessed the highly productive, species-wide structures of our human embodiment. The $S H$ becomes an authoritative text, however, if it is established that the early Franciscan practices and teachings recorded here resonate positively with our contemporary science, and in more than incidental

51 Kane, 'Rethinking Free Will,' p. 390.

52 Nancey Murphy and Warren S. Brown, Did My Neurons Make Me Do It? Philosophical and Neurobiological Perspectives on Moral Responsibility and Free Will (Oxford: Oxford University Press, 2007). 53 Robert Kane, 'Libertarianism,' in John Martin Fischer, Robert Kane, Dirk Pereboom, and Manuel Vargas, Four Views on Free Will (Oxford: Blackwell, 2007), pp. 5-43; Kane, 'Rethinking Free Will,' pp. 384-401. 
ways. We are looking then for evident convergence between science and text in significant themes. If this does indeed appear to be the case, then we may still judge that this is purely the result of chance. But it would seem more likely that Francis did indeed lead a distinctive life in which the structures of the human, which is to say our capacity to belong deeply in the world, came into view with exceptional force and particular clarity.

The $S H$, which is based upon the extensive imitation of St Francis of Assisi, then becomes the reflective product of that dynamic and encounter. Of course, we also have to consider whether further factors may have been in play here, such as the rise of the 'vow' as distinct from the 'oath', with its commitment to a non-enclosed religious life. ${ }^{54}$ Unlike the monastic orders, the mendicant structure of the religious life allowed the followers of St Francis to observe him in all kinds of different contexts of living, which must have enriched their understanding of his vocation. Early Franciscan tradition was distinctive in its repeated emphasis on the production of biographies and records of personal encounter with their charismatic founder, as it was in the tendency of the Franciscan authors of the $S H$ to think 'like a community, not merely as a group of scholars who happened to be working at the same institution. ${ }^{55}$ The text of the $S H$ is altogether more heuristic and exploratory than the Dominican Summa Theologiae of Thomas Aquinas for instance, in which the pedagogical lucidity and thematic unity of the text is the dominant formal structure. It may be too that the influence of the Islamic thinker Avicenna among the Franciscans in the early decades of the 13th century added a more concrete perspective, of encounter and interruption, than was typical of the later Aristotelianism. We can add here the particularly radical nature of the early Franciscan vow of poverty which may, starkly, have highlighted the theme of freedom. ${ }^{56}$

\section{Three Areas of Continuity}

There are distinctive factors surrounding the production of the text of the $S H$ therefore. But the key question concerning its authority for us today is focused in three particular areas of innovation. These are central to the philosophy and theology of the $\mathrm{SH}$ and the early Franciscan theology which it supports, as well as being of in-

54 John of La Rochelle's understanding of the importance of the vow in Franciscan life played an important part in the formation of the legal structure of the Franciscan Order. The dependence of the vow upon the Papacy, as enacted commitment to God, allowed the mendicants greater freedom of movement within the society of the day. See R. Saccenti, 'Beyond the Positive Law: The Oath and Vow as a Theological Matter Between the Twelfth and Early Thirteenth Century,' in The Summa Halensis: Doctrines and Debates, ed. Lydia Schumacher, Veröffentlichungen des Grabmann-Institutes zur Erforschung der mittelalterlichen Theologie und Philosophie (Berlin: De Gruyter, 2020), pp. 251-74. 55 Schumacher, Early Franciscan Theology, pp. 41-54, 29.

56 I am grateful to Mary Beth Ingham, CSJ for this insight. 
terest from the perspective of contemporary science. The first of these concerns the philosophy of the 'transcendentals' as this classical Greek theme was developed by the early Franciscans. The second is the very strong Franciscan account of 'freedom' which begins in the $S H$ and flowers in Scotus, while thirdly we will consider their understanding of 'natural law'.

\section{The 'Transcendentals'}

Religions tend to be heavily invested in cosmological accounts of reality, and nowhere does this come more clearly into view than in the medieval engagement with the theme of the 'transcendentals'. This begins with the work of Philip the Chancellor in his Summa de Bono, dating from the 1220s, perhaps during the lifetime of St Francis himself (1181-1226). Philip adapts the classical, principally Platonic, inheritance with his construction of a medieval 'science of metaphysics' ${ }^{57}$ Jan Aertsen identifies five elements here: in the first place 'being', followed by the three terms of 'one', the 'true' and the 'good', each of which is 'convertible' with the others and should help us to understand the properties of 'being' in the formation of a science of metaphysics. Aertsen's fifth element here is 'epistemology' and the fact that these transcendental terms 'come first' in so far as they ground our experience of the concrete world as such. ${ }^{58}$

The $\mathrm{SH}$ is distinctive in the central role that it gives to the transcendentals. Another Franciscan text (which is believed to have been written by a student of Alexander of Hales) also innovates in that it unequivocally emphasizes the role of beauty as a further transcendental term which integrates the other transcendental terms of oneness, truth and goodness in the grasping of being as such..$^{59}$ This particular view does not become an established part of Franciscan tradition, but nevertheless there is a repeating emphasis on aesthetics and aesthetic reasoning in the thought of Bonaventure and Duns Scotus for instance. ${ }^{60}$

In Scotus the concept of theology as a 'science of praxis' has a central role. This roots his anthropology in space and time and in our embodied human particularity. But Scotus also develops an innovative metaphysics of particularity or what he calls haecceitas ('this-ness'). Haecceitas signals that we cannot define real things through

57 For an overview of this term, see Jan Aertsen, Medieval Philosophy as Transcendental Thought (Leiden: Brill, 2012), pp. 1-11.

58 Aertsen, Medieval Philosophy as Transcendental Thought, pp. 10 -11.

59 Aertsen, Medieval Philosophy as Transcendental Thought, p. 169. The text referred to is the Tractatus de transcendentalibus entis conditionibus (Assisi, Biblioteca Communale, Cod. 186), in Franziskanishe Studien 41 (1959), pp. 41-106.

60 In the case of the Itinerarium, Denys Turner attributes the emphasis upon beauty to Bonaventure's 'interiorized hierarchy'; see Denys Turner, The Darkness of God: Negativity in Christian Mysticism (Cambridge: Cambridge University Press, 1995), pp. 102-34. 
the language either of 'matter' or 'form' alone, but neither can we define them through 'matter and form' in combination (as was the norm). This also is too abstract. Rather, his term haecceitas points to real things as being a particular combination of both 'matter' and 'form' in this space and time. ${ }^{61}$ Scotus' emphasis on particularity and 'this-ness' yielded a new metaphysics of 'things': spatio-temporal objects which endure. Scotus also holds that such objects participate in the beauty of the original divine creation. ${ }^{62}$

In effect then, Scotus' 'scientific' innovation of a haecceitas which inheres in real and particular things, structured in complex space and time, and which are beautiful, stands as a parallel to the harmonies and supporting cosmic 'symmetry' of our contemporary physics. We would call this 'translational invariance' today. In the previous section we addressed the question of a human form of 'translational invariance', pointing to the harmonies of top-down reasoning in demanding decision-making as we struggle to discern the right thing to do in complex situations. Here neuroscience freely uses the language of harmonics, and the integration of contrasting harmonic systems. But in a further parallel, Scotus too speaks of moral decisionmaking in terms of 'beauty' and 'harmony'.

Scotus tells us that 'the moral goodness of an act is a kind of decor it has, including a combination of due proportion to all to which it should be proportioned (...) and this especially as right reason dictates should pertain to the act. ${ }^{93}$ What mediates between the concrete particularity of the real and the sublimity of heaven is the harmonic order of moral reasoning which, for Scotus, manifests a love not for 'advantage' but rather for 'justice'. ${ }^{64}$ For Scotus, right reasoning here expresses due proportions which manifest as beauty through right relations. Wolter summarizes Scotist 'moral goodness' as 'a kind of moral beauty or comeliness. (...) Like beauty, it "is not some absolute quality," but rather a harmonious relationship of many items (the faculty of the will, the object it seeks, the conditions under which it does so etc. ${ }^{65}$

Scotus does not speak of the pulchrum or beauty in terms of the 'transcendentals' then, but he does understand 'real things' as harmonic structures of 'this-ness' (reflecting the original creation) and the human self as capable of conforming to harmonies through 'right reasoning' which is a reasoning of right relations. Moreover, in his engagement with 'moral reasoning', it seems that Scotus is concerned with

61 See Mary Beth Ingham and Mechthild Dreyer, The Philosophical Vision of John Duns Scotus: An Introduction (Washington DC: Catholic University Of America Press, 2004), pp. 108-16. See also Oliver Davies, Theology of Transformation: Faith, Freedom and the Christian Act (Oxford: Oxford University Press, 2013), pp. 202-5.

62 Allan B. Wolter, Duns Scotus on the Will and Morality (Washington DC: Catholic University of America Press, 1997), p. 19.

63 John Duns Scotus, Ordinatio I, d. 17 (nn. 62-67), in Wolter, Duns Scotus on the Will and Morality, p. 167.

64 Wolter, Duns Scotus on the Will and Morality, pp. 39-41.

65 Wolter, Duns Scotus on the Will and Morality, p. 47. 
what we might call 'human translational invariance'. In fact, we can suggest that he is concerned here both with finite, situational change which maintains the integrity of our personhood over time and space and with infinite 'human translational invariance', whereby the human begins to participate in the infinite life of the Creator.

For Scotus then, the sublimity of the vision of God in heaven, on the one hand, and the structures of the concrete real on the other, are connected by our own rootedness in the here and now, which is the domain of our moral decision-making. He develops a cosmic image of creation which pivots around our human capacity to will the right thing, in the order of concrete decision-making, thus grounding processes of reasoning which manifest right relations in the nature of reality itself.

\section{Freedom}

As we have seen, our evolutionary history suggests that the emergence of advanced language is late, and that freedom of choice is an intrinsic property of our advanced linguistic consciousness. The power of reasoning and coming to judgment is itself a function of advanced language and manifests for us as the sense that we are free in what we think and do. Early Franciscan traditions are permeated with the thematic of freedom (which may indeed reflect the existential weight of the vow of radical poverty), whereby what is believed is governed as much by the will as it is by reason. The will has the power to choose either good or evil. It shapes how we see the world.

As noted above, evolutionary science and the neuroscience of decision-making suggest the primary role of control in our advanced linguistic consciousness. This cuts two ways however. The structure which is in play here is the 'inhalation-exhalation' effect which means that the internalization of tools leads to new levels of penetration into the environment. Advanced language constitutes the second phase in this key evolutionary dynamic of niche construction. The internalization of thousands of 'signs' allows the linguistic mind to penetrate into the environment, hugely expanding our sense of being in a 'world'. Advanced language both shapes reality and receives it. ${ }^{66}$ It is this receptivity of our linguistic consciousness which allows the speaking other to enter into us (as part of the world around us) through the social cognition system, in ways that give us access to how they think and feel. With the emergence of advanced language from within the social cognition system, we begin to know the mind of the other and become capable of joint decision-making.

As we saw earlier, it is this dynamic of the primary reception of the other which shapes the different kinds of reasoning we do, as either 'theoretical reasoning', 'practical reasoning' or, most significantly, 'community reasoning'. It is only in the third of these that we accept the priority of the communicating presence of the human other which is established in the social cognition system, at the level of our pre-thematic

66 Rowan D. Williams, The Edge of Words (London: Bloomsbury Continuum, 2014), pp. 66-94. 
embodiment, to determine the nature of our conscious decision-making. This now includes the other, not as an object to be subjected to my control, but rather as a person who is recognized as a 'friend'.

The key dynamic here lies in the difference between instrumentalizing or controlorientated modes of reasoning and the refusal of this, through the determination to make a properly open or non-controlling decision. Of course, instrumentalizing or control-orientated modes of reasoning have their place, but our social viability calls for open interpersonal relations which manifest respect and equality and are foundationally inclusive. For Scotus, three kinds of freedom predominate: velle ('I want'), nolle ('I don't want') and non velle ('my mind is still open'). ${ }^{67}$ Velle and nolle both point to a form of self-interested possessiveness (affectio commodi), while the third kind of willing is a conceptual innovation which points to our capacity not to come to premature judgment but rather to remain open in our moral questioning. This is termed affectio iustitiae, or 'love for justice'. ${ }^{68}$ Both Robert Kane and Duns Scotus are concerned with human freedom, exercised in contexts of complex moral judgment, and each, in their own terms, points to the primary structure of human integrity as maintaining an open responsivity in the face of the complex real. The philosopher Paul Janz captures this very well when he describes it as 'a finality of non-resolution' where 'finality' points to a 'decision for openness' in which we accept a demanding situation unreservedly and resolve to 'stay with it'. ${ }^{69}$

In a way that recalls for us quantum theory in our own times, Scotus holds that the whole of the created order is contingent and free. He believes, with Augustine, that the divine will itself is creative and free, and so the radical freedom in our moral choosing is the product of our own createdness, itself reflecting the original divine free will by which the world was created and is held in being. ${ }^{70}$ It is only because the world is contingent and free that human beings can also be free within contingency and can discover in this freedom their own reciprocal mode of moral creativity. ${ }^{71}$

Finally, in parallel with the 'infinite human translational invariance' of the previous section, we can see here too a theological version - in this case the Trinity which lends thinking about 'justice' a universalist dimension. The Franciscans

67 Ingham and Dreyer, The Philosophical Vision of John Duns Scotus, pp. 146-72.

68 John Duns Scotus, Ordinatio II, d. 6, in Wolter, Duns Scotus on the Will and Morality, pp. 295-302. For a discussion of this text, see Allan B. Wolter, 'Native Freedom of the Will as a Key to the Ethics of Scotus,' in The Philosophical Theology of John Duns Scotus, ed. Marilyn McCord Adams (Ithaca, NY: Cornell University Press, 1990), pp. 148-62. See also Simon Francis Gaine, Will There be Free Will in Heaven? Freedom, Impeccability and Beatitude (London; New York: T\&T Clark, 2003), pp. 119-36. 69 Paul D. Janz, God, the Mind's Desire: Reference, Reason and Christian Thinking (Cambridge: Cambridge University Press, 2004), pp. 19-23.

70 See John Duns Scotus, Ordinatio IV, d. 7 and Ordinatio III, suppl. dist. 37, in Wolter, Duns Scotus on the Will and Morality, pp. 195-207.

71 Ordinatio II, dd. 34-37, q. 5, n. 96, in Ingham and Dreyer, The Philosophical Vision of John Duns Scotus, pp. $138-45$. 
were drawn by the concept of condilectio as 'shared love' or 'co-love'. As Lydia Schumacher states this: 'co-love occurs when a third is loved by the two in harmony and collectively (concorditer et socialiter) so that the two persons' affects are fused to become one because of the flame of love for the third. ${ }^{72}$ This is a version of Trinitarian theology, which originates in Richard of St Victor, and which places a particular emphasis on the 'third' beyond the dyad of the 'inter-face'. We can read this today as a particular appeal to the cultural extension of love, as based in the social cognition system, into larger scale modern society, along the axis of a universalist 'love for justice'.

\section{Natural Law}

Finally, we come to the question of 'natural law' which was a fundamental topic of debate throughout the medieval period. It has proved difficult to defend this idea in the modern period however, with our greater awareness of the diversity of ethical systems and the challenge of defending any kind of normativity. The understanding of the $S H$ is that "natural law is knowledge of the eternal law impressed in the soul. ${ }^{, 73}$ We read: 'as the image, which is in the seal, impresses, and the image which is in the wax is impressed and is the image of that which is in the seal, so it is here, because the eternal law impresses, and the natural law is impressed in the soul. ${ }^{74}$ In Riccardo Saccenti's summary, 'the eternal law is received by rational creatures and thus it is made present to their minds through impression rather than through an autonomous search on the part of reason itself. ${ }^{, 75}$

Here the force of impressa or 'impressed' is considerable, since this is a physical image and contrasts with Thomas Aquinas' later definition of natural law as being grounded in our powers of reasoning. Thomas defines natural law in terms of the 'participation of the rational creature in the eternal law. ${ }^{76}$ This means that it is 'not something received by rational creatures but (...) [is itself] a product of reason': a form of knowledge produced by the practical intellect. ${ }^{77}$

The debates around natural law have concerned the locus of law in us, to which we respond through conscience or a sense of the right thing to do. The later Aristo-

72 Schumacher, Early Franciscan Theology, p. 174.

73 Riccardo Saccenti, 'From the "lex aeterna" to the "leges addictae": John of La Rochelle and the Summa Halensis,' in The Summa Halensis: Doctrines and Debates, ed. Lydia Schumacher, Veröffentlichungen des Grabmann-Institutes zur Erforschung der mittelalterlichen Theologie und Philosophie (Berlin: De Gruyter, 2020), pp. 227-50, on p. 245.

74 Saccenti, 'From the "lex aeterna" to the "leges addictae," p. 245. Alexander of Hales, Doctoris irrefragabilis Alexandri de Hales Ordinis minorum Summa theologica (SH) 4 vols (Quaracchi: Collegium S. Bonaventurae, 1924-48), IV, P2, In2, Q1, C1 (n. 241), Ad obiecta 2, p. 340.

75 Saccenti, 'From the "lex aeterna” to the "leges addictae," p. 245.

76 ST Ia-IIae, q. 91, a. 2, cited in Saccenti, “From the "lex aeterna” to the "leges addictae,” p. 248. 77 Saccenti, 'From the "lex aeterna” to the "leges addictae,”' p. 248. 
telian account prioritizes reason or mind as producing a form of moral knowledge which is not practice-orientated or habit-forming knowledge but rather rationallyconstituted understanding which shares in the nature of eternal law. The $S H$ on the other hand, envisages the locus of natural law in us to be bound up with the material concept of impressa.

Today's neuroscience offers a very different conception of 'conscience' and 'law'. Freedom of choice is a function of our advanced linguistic consciousness, while the strong sociality which is a central part of our evolutionary inheritance is 'pre-thematic' and embedded within the interacting, participative, complex systems of our social cognition. The first choice we have to make as free agents is whether and to what extent we shall allow ourselves as conscious, self-possessing mind to conform with our own other-orientated social cognition which is already a 'given' of our biology. As we have seen, as conscious agent we like to retain control, while an unconditional acceptance of the other entails at least a significant loosening of control. There is an inevitable tension then between those systems that support self-possessing consciousness with its power of choice, on the one hand, and the deep-set, participative, pre-thematic systems which are our long-term inheritance on the other.

The concept of a natural law which is 'impressed' in us - with all the associations of this word with materiality and embodiment - sits well with the distinction between pre-thematic social cognition and self-aware decision-making. We have to allow our social cognition to bond with the social cognition of others, if we wish to have any close allies and friends. But at the same time, this 'law' is not something that we devise for ourselves. Rather it is a given of time and space and of our longterm evolutionary history. Our social cognition system constitutes an open-ended, inclusive, interactive and evaluative center in us which grounds our capacity for social bonding, where we will to consent to renounce manipulative control over the other. Here the body's prior 'option for the other' is in play. In this sense our social cognition system functions in a way parallel to the medieval concept of 'natural law'.

And there is a final dimension to natural law here. In the $S H$, natural law is associated with 'divine commands'. These are culturally mediated, moral imperatives which directly address the thinking mind. The combination of pre-thematic, inherited social cognition, and its 'option for the other,' with the divine commands of a religious culture such as that delineated in the $S H$, secures the strong interplay between body and mind: the pre-thematic and the conscious self. Such explicit moral imperatives within the community then allow for ever deeper levels of freedom, expressed in the personal unity of body and mind, which begin to take us beyond virtue ethics. ${ }^{78}$

78 Lydia Schumacher, 'Divine Command Theory in Early Franciscan Thought: A Response to the Autonomy Objection,' Studies in Christian Ethics 29:4 (2016), pp. 461-76. 


\section{Conclusion}

The original sources drawn upon in the scientific sections of this article reflect high levels of epistemic authority, based in the empirical scientific method. This is necessarily a specialist discourse. The questions being addressed however increasingly concern significant dimensions of human existence as such. They engage our deep history in both evolutionary and neuroscientific terms and clearly they potentially constitute a valuable resource for our self-understanding today.

To the extent that there is found to be a congruence between contemporary science and early Franciscan thought, as represented by the Summa Halensis, we can legitimately speak of the latter as an authoritative text whose significance goes beyond its own times, reaching even to our own. But what follows from this? Of course, such authority underlines the potential reception today of early Franciscan philosophical and theological resources, as more is retrieved and communicated. This is a religious text which can potentially combine with science in innovative ways, for a religious readership. But this brings a second question into play. The Summa Halensis is not just a religious text: it is also an anthropological one, within a cosmic framework which resonates with science today.

The phenomenon of 'enlightenment' presupposes a configuration of science and culture in combination. This was the character of the Enlightenment which shaped Western modernity. We may be entering a period of second Enlightenment, however: one based not in the technological side of our human evolution but rather in the social side. If this is the case, then entirely new dialogues between science and social traditions may be on the horizon. Such traditions, with the $\mathrm{SH}$ a prominent and perhaps exceptional case, will be needed not only as resources for understanding our past but also for shaping our future. An Enlightenment is produced through the combination of science and culture, and the shape of a social Enlightenment will rely upon long term textual sources which can encode the new science within liberating and imaginative narratives. These may be able to foster community within large scale populations and between large scale populations in our global spaces. The narrative, imaginative, and practical styles of religious traditions can be powerful drivers of social change. If our new scientific self-understanding as human can be discretely supported by a text such as the Summa Halensis, then it might even be possible to develop a new kind of scientific genre: one in which a social kind of scientific knowledge is transferred into populations through the skills of image and narrative, with authority. 
